\title{
A short course in planning, development and evaluation of community mental health services
}

\author{
Robin Powell, Geraldine Strathdee and Graham Thornicroft
}

\begin{abstract}
In response to the expressed needs of trainees for training in the planning development, and evaluation of mental health services, a short course was designed and is described here. The course was run several times and proved fiexlble enough to be presented to elther multidisciplinary, inter-agency audiences or to a solety medical audience.
\end{abstract}

In recent years there has been a change of emphasis in the planning and practice of mental health services within the United Kingdom. Traditional hospital-based, medically dominated services are giving way to more communityoriented, multidisciplinary provision. Despite calls for medical education to take account of these changes (Connolly \& Marks, 1989; Littlejohns et al, 1992), the deficits in higher training continue (Brooke, 1981: McClelland et al, 1993).

The composition of a suitable training syllabus has taxed educators since 1968 when the Royal Commission exhorted that "every psychiatrist should be familiar with...the conduct of community psychiatry". Two recent publications appear to have reached a consensus (Connolly \& Marks, 1989; McClelland et al, 1993). The proposed subject matter comprises three main components: Core theoretical knowledge, encompassing the philosophy and history of community care, the epidemiology of mental disorders, the bio-psychosocial nature of aetiology, natural history, and management of mental disorders, and the theory of crisis intervention; Multidisciplinary working, including how to optimise the team's human resources, how to work with families and patient groups, making domiciliary assessments, and access to and liaison with external resources (both people and facilities); and Planning and managerial issues such as how to train junior doctors, how to manage a caseload, how to manage a budget. how to evaluate changes made in a care system, how to do quality assurance, NHS and social services management, and the development of future services.

\section{Rationale for the course}

A study of the training needs of Maudsley junior doctors (McClelland et al, 1993) found that while $80 \%$ valued their clinical attachments, they lacked sufficient opportunity to develop skills in the planning and evaluation of community services. In response to this unmet need the authors developed and ran two training courses in the planning, development, and evaluation of community mental health services. The first was for a multidisciplinary, inter-agency audience including medical, nursing and occupational therapy staff and management staff from the local social and mental health services. The second course (purely for organisational reasons) was provided for senior registrars of the Maudsley and Bethlem Royal Hospitals.

\section{Course objectives}

(1) To impart to each participant an understanding of the academic basis and the theoretical context of service development in a wide range of areas

(2) To expose participants to the full breadth of national and international models of service provision

(3) To equip senior trainees for their future careers as consultants in which they will play a lead role in the development of community services.

\section{Course structure and content}

The course comprised six two-hour sessions held on two consecutive days. The sessions focused on: planning a comprehensive district service; comprehensive crisis intervention: primary care 
Table 1. Objectives, assignment and tasks set for a typical syndicate workshop

Planning a comprehenstve service

Objectives

1) To have an understanding of the full range of senvices necessary for the provision of a comprehensive district service

2) To define which of these services can be provided as generic sector services and which should be centrally based specialist senvices

3) To define the organisational frameworks, within both the health service and other community agencies, necessary for planning community care.

\section{Asalgnment}

You are a newly appointed clinical director. Your district has just made the deciston to move the bulk of its services from a hospltal base into the community. How would you commence the planning process?

Tasks

a) List the range of services you would wish to provide

b) Outline the sections of your service specification contract with your local purchaser (e.g. SELCA)

c) Define the service level agreement basis of your business planning.

and community psychiatry; assertive outreach and case management; day care models and philosophies; and how to evaluate your service.

\section{Course format}

A relaxed, participative style of teaching was adopted with each session, including a formal presentation of the theoretical framework and basic concepts; small-group 'syndicate-workshops' using 'brainstorming' techniques to encourage participants to combine theory with their own experlence, and to address current planning issues in their own service; a plenary session in which workshops were summarised; and a final interactive, informal, large-group session allowing consolidation and further development of ideas.

Course material provided for each session included a reference list, compiled to include seminal texts, recent substantive reviews, and papers which describe and/or evaluate service models (particularly if they included details of the service structure); an annotated bibliography composed of descriptions of a wide range of relevant service models and in particular details of service operational policy, staffing levels, casemix, research methodology and results of evaluations; and syndicate workshop objectives and tasks (see Table 1).

\section{Course evaluation}

A total of 38 people attended the two courses. Evaluation comprised the completion of a structured questionnaire which identified the participants' opinions of: 1) the clarity of course objectives; 2) comprehensibility of content; 3) relevance to career; 4) use of visual aids; 5) stimulation to investigate further; 6) clarity of written material; 7) whether material was handed out sufficiently far in advance; 8) opportunity for application of ideas in workshops; 9) use made of own experience; 10) involvement; 11) level of interest: 12) opportunity to express views; 13) enjoyment; and 14) balance between theory and discussion. These were scored on a six-point modified-Likert scale. Four open questions invited general comments and recommendations for future courses. Results over both courses were pooled. Responses to questions 1-3 were overwhelmingly positive with a mean response to each question of $\geqslant 5.0$ ( $95 \%$ confidence intervals $\leqslant \pm 0.36$; s.d. $\leqslant 1.5$ ). Moderately posittve responses were obtained to questions 4-6 and 9. The response to question 7 was ambivalent.

\section{Summary and implications for future training}

Results from the students' evaluation are encouraging: the course participants were satisifed with all the sessions. In particular attenders thought that course objectives and content were clear and balanced; the course was relevant, stimulating and enjoyable; and that individuals had ample opportunity to participate. Previous attempts to develop managmenet courses have been criticised for neither being practically oriented enough nor relevant to the NHS (Jadresic, 1992). It is the opinion of the authors that this style of course is well suited to the current needs of health services as described in The Health of the Nation (DoH, 1994). In the experience of the course organisers and teachers having a multidisciplinary, multi-agency composition of participants enhanced the learning experience. The greater breadth of expertise informed the workshop sessions allowing more creative development of ideas in service planning. the process of mutual learning was amplified, people were introduced to and familiarised with each other's agencies, and local networking was facilitated.

The authors are in the process of developing this course further for a national audience and would welcome comment. A course manual can be obtained from the authors.

\section{Acknowledgements}

We acknowledge the inspiration and support of Dr Stuart Checkley, Dean of the Institute of 
Psychiatry. Grateful thanks are due to Sarah Christie-Brown and Chris Hartshorn for research and administrative assistance.

\section{References}

BROOKE. C. P. B. (1981) Postgraduate psychiatry. Medical Education. 15, 335-339.

CONNOUY, J. \& MARKS, I. (1989) Community orlented psychiatric care. Psychiatric Bulletin, 13, 26-27.

DEPARTMENT OF HEALTH (1994) Health of the Nation Key Area Handbook (2nd edn). London: HMSO.

JADRESIC, D. (1992) Management training: what do we need? Psychiatric Bullettn, 16, 86-87.

LTTLENOHNS, C. S., WIIKInson, G. \& MURPHY, E. (1992) Training psychiatrists for work in the community. Psychiatric Bulletin, 16, 23-24.
MCCleUAND, L., STRATHDEE, G. \& THORNICROFT, G. (1993) Training needs in social and community poychiatry: a survey of Maudsley trainees (unpublished research report).

*Robin Powell, Training Development Senior Registrar and Course Organiser, PRISM Unit, The Institute of Psychiatry. DeCrespigny Park, London SE5 8AF. Geraldine Strathdee, Consultant Community Psychiatrist, The Maudsley Hospital and PRISM, Denmark Hill, London SE5 8AZ; and Graham Thornicroft, Director of PRISM, The Insttute of Psychiatry, DeCrespigny Park, London SE5 8AF

*Correspondence: Dr Robin Powell, Consultant Psychiatrist, Park Royal Centre for Mental Health, Central Middlesex Hospital, Action Lane, London NW10 7NS

\title{
Mental Health Care in China 中 國的精神 保 健 制 度
}

\author{
State Policies, Professional Services and Family Reponsibilities \\ by Veronica Pearson
}

This book traces the development of psychiatric services in the People's Republic of China. Historical, policy and legal frameworks are constructed to provide a context in which psychiatric services may be better understood. The experience of both staff and patients in one particular hospital is examined in detail. The book raises questions about the similarities in the experience of psychiatric illness across significantly different cultures.

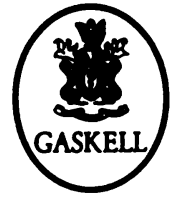

\section{$\bullet £ 12.50 \bullet 218 p p . \bullet 1995 \bullet$ ISBN 0902241745}

Available from bookshops and from the Publications Department, Royal College of Psychiatrists, 17 Belgrave Square,

London SW1X 8PG (Tel. 0171-235 2351, extension 146) 